\title{
Saliva pH Changes in Patients with High and Low Caries Risk After Consuming Organic (Sucrose) and Non-Organic (Maltitol) Sugar
}

\author{
Widowati W, Akbar SH, Tin MH \\ Faculty of Dentistry, International Islamic University Malaysia
}

\begin{abstract}
Introduction: Enamel demineralization is associated with decrease in saliva pH due to fermentation of sugar by oral commensal. Thus, exploring the changing pattern of saliva $\mathrm{pH}$ is meaningful in dental caries prevention. The aim of this study was to compare the changing pattern of saliva $\mathrm{pH}$ after consuming different types of sweeteners (sucrose and maltitol). Methods: It was a case-control study involving 14 male patients attending IIUM dental clinic who were selected with the intention of getting seven patients with high caries risk ( DMFT $\geq 6$ ) and seven patients with low caries risk (DMFT $\leq 3$ ) with initial saliva pH interval of 6.5 to7.5. Patients were asked to consume snacks containing 8 gram sucrose and 8 gram maltitol as sweeteners. The changing $\mathrm{pH}$ values of the saliva were measured by Waterproof pHTestr 10BNC (Oakton, Vernon Hills, USA) seven times consecutively at 0 (before snack consumption), and at 5, 10, 15, 20, 30 and 60 minutes after snack consumption. The pH values of saliva of patients with low and high caries risk after consuming sucrose and maltitol were statistically analized by using Anova and Tukey-HSD tests at $a=0.05$. Result: There were significant differences in saliva pH changes between low-risk group and high-risk group after consuming sucrose and maltitol. Conclusion: The changing patterns of saliva $\mathrm{pH}$ in high-risk patients were lower than those of low-risk patients after consuming two types of snacks containing sucrose and maltitol.
\end{abstract}

KEYWORDS: Saliva pH, sucrose, maltitol, susceptability, dental caries

\section{INTRODUCTION}

Dental caries form through a complex interaction over time between acid-producing bacteria and fermentable carbohydrate and many other host factors, including teeth and saliva. The disease develops in both the crowns and roots of teeth, and it can arise in early childhood as an aggressive dental caries that affects the primary teeth of infants and toddlers. ${ }^{1}$ The influence of saliva on the caries process is fundamental. In some way, saliva affects all three of the components of Keyes classic Venn diagram of caries aetiology that is tooth, plaque, and substrate. ${ }^{2}$ According to the classification of WHO low caries risk group is one having 1.2-2.6 of DMF(t) index; while group having 4.6-6.5 of $\operatorname{DMF}(\mathrm{t})$ index is grouped into one with high caries risk. ${ }^{3}$

There is clearly a correlation between low salivary buffer capacity and dental caries experiences, ${ }^{4}$ and an additional study ${ }^{5}$ reported a similar result, although the data were not quite as strong. Sucrose is one of the main causes of caries formation, since it has low

Corresponding author:

Dr Widowati Witjaksono

Kulliyyah of Dentistry

International Islamic University Malaysia (IIUM),

Kuantan, Pahang, Malaysia.

Phone: 006-0139473801

E-mail: drwidowati@iium.edu.my molecular weight and easily dissolved. Thus, it can be quickly fermented by the bacteria and produce extracellular polysaccharide (dextrane and levane) which adheres to the teeth surface. ${ }^{6,7,8}$

Maltitol is a commonly used artificial sugar substitute and often goes by its common registered names of Maltisorb ${ }^{\circledR}$ or Maltisweet $\circledast$. It is a type of artificial sweetener known as a polyol or sugar alcohol; similar to table sugar in sweetness and texture, but does not promote dental caries and has half the calories in sugar. However, maltitol has side effects and hasn't been studied on humans long enough to know the full extent of any long-term dangers of consuming the sweetener. Until such studies are completed, it may be best to use maltitol in moderation or avoid it altogether. ${ }^{9}$

This study will highlight the factors that cause $\mathrm{pH}$ reduction of saliva and the dietary habit. Dietary habit is still the major factor causing dental caries as increase exposure time of sucrose in oral cavity will induce lowering of $\mathrm{pH}$ value by fermentation of this substrate by microorganism, especially Streptococcus mutans. ${ }^{10}$

The aim of this study is to investigate and explore the pattern of changes in saliva $\mathrm{pH}$ after consumption of different types of sweeteners in persons with high caries risk and low caries risk. The importance of exploring this change is for prevention of dental caries among population. 


\section{MATERIALS \& METHODS}

The subjects involved in this study were among the community of International Islamic University Malaysia, Kuantan Campus. Written informed consent was obtained from the subjects after the nature of the clinical trial procedures was explained.

14 patients were recruited for the study in selected random sampling with the criteria: male, 20-35 years, patients with low caries risk (DMF-t $\leq 3$ ) and patients with high caries risk (DMF-t $\geq 6$ ), oral cavity $\mathrm{pH}$ before treatment is $6.50-7.50$, non smoker and in a good general health. Sample were divided into two groups; one group was patients with low caries risk, and the other group with high caries risk and each group consisted of seven patients.
On the first day, all patients were asked to brush their teeth using the Roll method ${ }^{11}$ for two minutes using the same toothpaste, and they were not allowed to eat and drink for two hours. After two hours, they were asked to sit on a chair and told to spit around $\pm 2 c c$ of saliva in a reaction tube, or it reached 2 $\mathrm{cm}$ from the base of the tube. Then, the $\mathrm{pH}$ of their saliva was measured by using waterproof pHTestr 10BNC (Oakton). Afterwards, they were asked to chew 8 grams of snacks containing sucrose for a minute. In the fifth, tenth, fifteenth, twentieth, thirtieth, and sixtieth minute, they were asked to spit again about $\pm 2 \mathrm{cc}$ in the reaction tube. Then the saliva $\mathrm{pH}$ was measured and recorded. Treatment on the second day, was the same as had been done on the first day. However, the snack containing sucrose was replaced with another snack containing maltitol. The data of saliva $\mathrm{pH}$ measurement was statistically analyzed using Anova test, and Tukey-HSD test at $\mathrm{a}=0.05$.

14 Patients

7 Patients

With low caries risk (DMF-t $\leq 3$ )

$\mathrm{pH}$ oral cavity $6.50-7.50$

(before treatment)

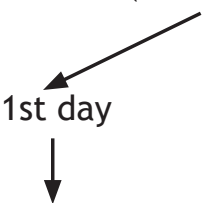

Brush using Roll

method (2 min)

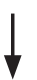

No eat \& drink<smiles>[3H][3H]</smiles>

Spit around $2 \mathrm{cc}$, then

$\mathrm{pH}$ measurement ( $\left.\mathrm{O}^{\prime}\right)$<smiles>[3H][3H]</smiles>

Chewing snack containing sucrose (1 $\mathrm{min}$ )<smiles>[3H][V]</smiles>

$\mathrm{pH}$ measurement with time interval as below

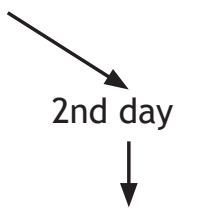

Brush using Roll method (2 min)<smiles>[3H][CH]</smiles>

No eat \& drink

Spit around $2 \mathrm{cc}$, then $\mathrm{pH}$ measurement ( $\left.\mathrm{O}^{\prime}\right)$<smiles>[13CH3]</smiles>

Chewing snack containing maltitol (1 $\mathrm{min})$

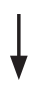

$\mathrm{pH}$ measurement with time interval as below
7 Patients

with high caries risk (DMF- $\mathrm{t} \geq 6$ )

$\mathrm{pH}$ oral cavity $6.50-7.50$

(before treatment)

$$
\mid
$$

similar treatment procedure

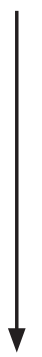

Chewing for

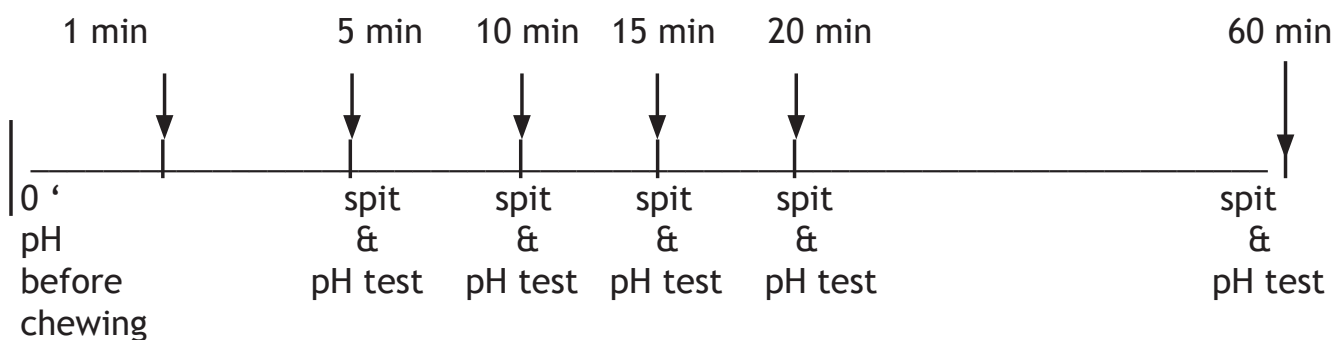

Figure1. Flow chart of treatment procedure 


\section{RESULTS}

Table 1. The Average value and standard deviation of saliva pH based on the type of caries, the type of sweeteners and the time after chewing of either sugar or maltitol.

\begin{tabular}{|c|c|c|c|c|}
\hline Type of Caries & Type of Sweetener & Time & Mean Value & $\begin{array}{l}\text { Standard } \\
\text { Deviation }\end{array}$ \\
\hline \multirow{14}{*}{$\begin{array}{l}\text { Low Caries } \\
\qquad \mathrm{n}=14\end{array}$} & \multirow{7}{*}{$\begin{array}{l}\text { Sucrose } \\
n=7\end{array}$} & 0 minute & 7.3414 & .08071 \\
\hline & & 5th minute & 7.1214 & .05273 \\
\hline & & 10th minute & 6.9414 & .12061 \\
\hline & & 15th minute & 6.8214 & .11291 \\
\hline & & 20th minute & 6.8514 & .16345 \\
\hline & & 30th minute & 7.0714 & .12602 \\
\hline & & 60th minute & 7.2257 & .07764 \\
\hline & \multirow{7}{*}{$\begin{array}{l}\text { Maltitol } \\
\mathrm{n}=7\end{array}$} & 0 minute & 7.3286 & .06466 \\
\hline & & 5th minute & 7.4000 & .15022 \\
\hline & & 10th minute & 7.1343 & .06876 \\
\hline & & 15th minute & 7.0343 & .08080 \\
\hline & & 20th minute & 7.1400 & .08832 \\
\hline & & 30th minute & 7.2471 & .07499 \\
\hline & & 60th minute & 7.3914 & .11097 \\
\hline \multirow{14}{*}{$\begin{array}{l}\text { High Caries } \\
\mathrm{n}=14\end{array}$} & \multirow{7}{*}{$\begin{array}{l}\text { Sucrose } \\
n=7\end{array}$} & 0 minute & 6.8814 & .17430 \\
\hline & & 5th minute & 6.5271 & .18319 \\
\hline & & 10th minute & 6.2143 & .40307 \\
\hline & & 15th minute & 6.1114 & .41835 \\
\hline & & 20th minute & 6.2300 & .40336 \\
\hline & & 30th minute & 6.4100 & .42802 \\
\hline & & 60th minute & 6.5371 & .40442 \\
\hline & \multirow{7}{*}{$\begin{array}{l}\text { Maltitol } \\
n=7\end{array}$} & 0 minute & 6.9943 & .16102 \\
\hline & & 5th minute & 6.7900 & .16931 \\
\hline & & 10th minute & 6.5843 & .15393 \\
\hline & & 15th minute & 6.4629 & .14773 \\
\hline & & 20th minute & 6.6200 & .17550 \\
\hline & & 30th minute & 6.7586 & .16886 \\
\hline & & 60th minute & 6.8957 & 15065 \\
\hline
\end{tabular}

Saliva pH in both groups of patients (with low and high caries risks) had the highest $\mathrm{pH}$ at the initial time and the lowest $\mathrm{pH}$ at the fifteenth minute after consuming snacks containing sucrose and maltitol.

The analysis of variance showed that the type of caries $(F=363.69 ; p=0,00)$, type of sweetener $(F=68.88$; $\mathrm{p}=0.00)$, and time $(\mathrm{F}=22.71 ; \mathrm{p}=0.00)$ after chewing affected the saliva $\mathrm{pH}$. Further analysis by Tukey HSD showed that there was significant change $(p<0.05)$ between saliva $\mathrm{pH}$ of patients in low and high caries risks. It was also found that there was significant difference $(p<0.05)$ in saliva $\mathrm{pH}$ after consuming sucrose and maltitol sweetener. 
Table 2. Degree of significance in each interval time of patients with low caries after chewing snacks containing sucrose and maltitol

\begin{tabular}{lllllllll}
\hline $\begin{array}{l}\text { Type of } \\
\text { Sweetener }\end{array}$ & $\begin{array}{l}\text { Time } \\
\text { (minute } \\
\text { after) }\end{array}$ & 0 & 5 & 10 & 15 & 20 & 30 & 60 \\
\hline \multirow{5}{*}{ Sucrose } & 0 & - & $0.009^{*}$ & $0.000^{*}$ & $0.000^{*}$ & $0.000^{*}$ & $0.001^{*}$ & 0.453 \\
& 5 & $0.009^{*}$ & - & 0.056 & $0.000^{*}$ & $0.001^{*}$ & 0.978 & 0.576 \\
& 10 & $0.000^{*}$ & 0.056 & - & 0.409 & 0.728 & 0.315 & $0.000^{*}$ \\
& 15 & $0.000^{*}$ & $0.000^{*}$ & 0.409 & - & 0.999 & $0.002^{*}$ & $0.000^{*}$ \\
& 20 & $0.000^{*}$ & $0.001^{*}$ & 0.728 & 0.999 & - & $0.009^{*}$ & $0.000^{*}$ \\
& 30 & $0.001^{*}$ & 0.978 & 0.315 & $0.002^{*}$ & $0.009^{*}$ & - & 0.197 \\
& 60 & 0.453 & 0.576 & $0.000^{*}$ & $0.000^{*}$ & $0.000^{*}$ & 0.147 & - \\
\hline \multirow{4}{*}{ Maltitol } & 0 & - & 0.799 & $0.008^{*}$ & $0.000^{*}$ & $0.010^{*}$ & 0.685 & 0.877 \\
& 5 & 0.799 & - & $0.000^{*}$ & $0.000^{*}$ & $0.000^{*}$ & 0.063 & 1.000 \\
& 10 & $0.008^{*}$ & $0.000^{*}$ & - & 0.454 & 1.000 & 0.311 & $0.000^{*}$ \\
& 15 & $0.000^{*}$ & $0.000^{*}$ & 0.454 & - & 0.387 & 0.371 & $0.000^{*}$ \\
& 20 & $0.010^{*}$ & $0.000^{*}$ & 1.000 & 0.387 & - & 0.371 & $0.000^{*}$ \\
& 30 & 0.685 & 0.063 & 0.311 & $0.003^{*}$ & 0.371 & - & 0.093 \\
\hline
\end{tabular}

*indicate significant difference

The results of Table 1, 2 and 3 and Figure 2 showed that the change in the pattern of saliva $\mathrm{pH}$ in patients with low caries risk, decreased in the fifth minute after consuming snacks containing sucrose compared to snacks containing maltitol; while the change in pattern of saliva $\mathrm{pH}$ of patients with high caries risk decreased in the tenth, fifteenth, twentieth, thirtieth and sixtieth minute after consuming snacks containing sucrose compared to snacks containing maltitol. The decrease of saliva $\mathrm{pH}$ in patients with high caries risk after consuming snacks containing sucrose was lower than patients with low caries risk in the fifth, tenth, fifteenth, twentieth, thirtieth and sixtieth minute while decrease of saliva $\mathrm{pH}$ in patients with high caries risk after consuming snacks containing maltitol was lower than patients with low caries risk at the interval time of the tenth, fifteenth, twentieth and thirtieth minute.

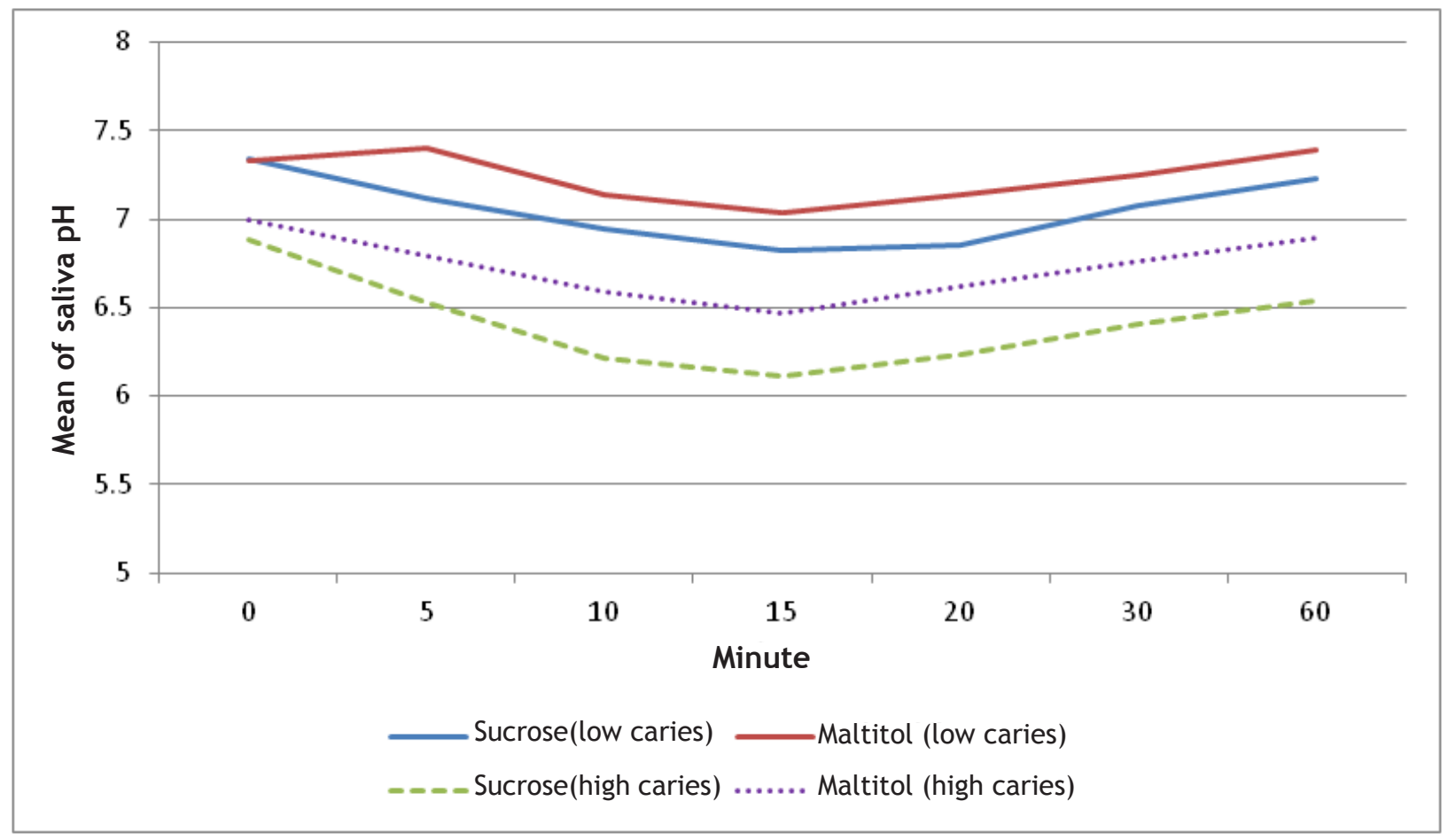

Figure 2. Saliva $\mathrm{pH}$ changes after consumption sucrose and maltitol among High caries $(\mathrm{n}=14)$ and Low caries $(n=14)$ 
Table 3. Degree of significance in each interval time of patients with high caries after chewing snacks containing sucrose and maltitol

\begin{tabular}{|c|c|c|c|c|c|c|c|c|}
\hline & $\begin{array}{l}\text { Time } \\
\text { (minute } \\
\text { after) }\end{array}$ & 0 & 5 & 10 & 15 & 20 & 30 & 60 \\
\hline & 0 & - & 0.531 & $0.020^{*}$ & $0.004^{*}$ & $0.024^{*}$ & 0.206 & 0.565 \\
\hline & 5 & 0.531 & - & 0.669 & 0.340 & 0.719 & 0.996 & 1.000 \\
\hline & 10 & $0.020^{*}$ & 0.669 & - & 0.998 & 1.000 & 0.984 & 0.636 \\
\hline \multirow[t]{7}{*}{ sucrose } & 15 & $0.004^{*}$ & 0.340 & 0.998 & - & 0.996 & 0.716 & 0.313 \\
\hline & 20 & $0.024^{*}$ & 0.719 & 1.000 & 0.996 & - & 0.965 & 0.687 \\
\hline & 30 & 0.206 & 0.996 & 0.948 & 0.714 & 0.965 & - & 0.994 \\
\hline & 60 & 0.565 & 1.000 & 0.636 & 0.313 & 0.687 & 0.994 & - \\
\hline & 0 & - & 0.237 & $0.000^{*}$ & $0.000^{*}$ & $0.002^{*}$ & 0.115 & 0.911 \\
\hline & 5 & 0.237 & - & 0.230 & $0.008^{*}$ & 0.447 & 1.000 & 0.880 \\
\hline & 10 & $0.000^{*}$ & 0.230 & - & 0.794 & 1.000 & 0.417 & $0.013^{*}$ \\
\hline \multirow[t]{4}{*}{ maltitol } & 15 & $0.000^{*}$ & $0.008^{*}$ & 0.794 & - & 0.541 & $0.021^{*}$ & $0.000^{*}$ \\
\hline & 20 & $0.002^{*}$ & 0.447 & 1.000 & 0.541 & - & 0.679 & $0.039 *$ \\
\hline & 30 & 0.115 & 1.000 & 0.417 & $0.021^{*}$ & 0.679 & - & 0.689 \\
\hline & 60 & 0.911 & 0.880 & $0.013^{*}$ & $0.000^{*}$ & $0.039^{*}$ & 0.689 & - \\
\hline
\end{tabular}

* indicate significant difference

\section{DISCUSSION}

The analysis of variance proved that patients at low caries risk have saliva $\mathrm{pH}$ higher than patients with high caries risk, after consuming snacks containing sucrose. Their saliva $\mathrm{pH}$ decrease more compared to saliva $\mathrm{pH}$ after consuming snacks containing maltitol. In the tenth, fifteenth, twentieth, and the thirtieth minutes, there were significant changes in saliva $\mathrm{pH}$ compared to the initial $\mathrm{pH}$ (the zero minute).

This study proves that patients having high caries risk have significant lower saliva $\mathrm{pH}$ compared to the patients with low caries risk; which is in accordance with the previous research. ${ }^{4}$

The type of sweetener in the snacks also affects the saliva $\mathrm{pH}$, and this is shown by the decrease of saliva $\mathrm{pH}$ after patients consumed snacks containing sucrose compared to of those who consume snacks containing maltitol. This may be because Streptococcus mutans cannot change maltitol into acid due to the absence of essential enzymes, even though maltitol can penetrate into the membrane of bacteria cell that reduces the activity of the glucosyltransferase. ${ }^{12}$ Sucrose can easily be fermented into lactic acid and piruvic acid. Thus, increasing the enzymatic activity of glucosyltransferase. ${ }^{13}$

This extracellular enzyme catalyzes the glucosyltransferase derived from sucrose, and it develops into glucan polymer and combines with the glucan binding protein to support the adherence of Streptococcus mutans to the teeth and the cell aggregation. ${ }^{12}$ Cariogenic bacteria such as Streptococcus mutans can use monosaccharide components (glucose and fructose) that are separated from disaccharide sucrose and energy derived from the bounding of the disaccharide to collect extracellular polysaccharide. This situation can accelerate the increase of plaque thickness, causing acidic environment of the teeth; and therefore, difficult to overcome by the buffer saliva and increases the risk of caries.

After consuming the sucrose type sweetener, the saliva $\mathrm{pH}$ decreased lower compared to consuming the maltitol type sweetener which cannot be fermented into acid. ${ }^{14}$ Generally, the pattern of saliva $\mathrm{pH}$ in patients having caries will show a decrease at the time intervals of the fifth, the tenth and the fifteenth minute and then increase again at twenty and thirty minutes after consuming snacks. At the sixtieth minute, the saliva $\mathrm{pH}$ is nearly the same as the initial $\mathrm{pH}$. This is in accordance with some researchers 8,12-14 who stated that the lowest pH occurs in about five to twenty minutes after consuming sucrose, and then gradually returns to normal. Saliva $\mathrm{pH}$ of patients having low caries risk increased at the fifth minute after consuming snacks containing maltitol. This may be caused by the calcium content found in milk, sodium bicarbonate and potassium in the snack having alkaline properties. ${ }^{8,15,16,17}$

The decrease in saliva $\mathrm{pH}$ at the fifth to fifteenth minute is due to of the presence of lactate and piruvic acids. The fermentation products of carbohydrate by the acidogenic bacteria cause the saliva $\mathrm{pH}$ to decrease. The decrease of saliva $\mathrm{pH}$ was above 5.5 as this study used the carbohydrate composition instead of pure sucrose; and it also 
consists of flour with polysaccharide type that is difficult to ferment. The increase of saliva pH after 20 minutes is caused by the capacity of saliva as a buffer that can neutralize acid thus; this can avoid the demineralization process. The balance between demineralization and remineralization can be quickly reached using high flow of saliva as an effective buffer. ${ }^{17}$

The changing pattern of saliva $\mathrm{pH}$ in patients with low caries risk after consuming snacks containing sucrose shows a decrease at the time interval of the fifth, the tenth, and the fifteenth minute, and increased again in the twentieth and the thirtieth minute. At the sixtieth minute, the saliva $\mathrm{pH}$ was nearly same as the initial $\mathrm{pH}$. While the analysis of the change in pattern of saliva $\mathrm{pH}$ of patients with low caries risk after consuming snacks containing maltitol shows the decrease at the time interval of tenth and fifteenth minutes. However, it started to increase at the twentieth minute. At the thirtieth and sixtieth minute, the saliva $\mathrm{pH}$ decreased till it reached the initial $\mathrm{pH}$.

The pattern analysis of saliva $\mathrm{pH}$ in patients with high caries risk after consuming snacks containing sucrose and maltitol shows a decrease at the time interval of tenth and fifteenth minute, and start to increase again after twenty minutes. In the thirtieth and sixtieth minute, the saliva $\mathrm{pH}$ was close to the initial $\mathrm{pH}$. The absence of significant difference in the low caries risk patients in the tenth, fifteenth, twentieth, thirtieth and sixtieth minute after consuming snacks containing sucrose and maltitol shows that the change in pattern of the saliva $\mathrm{pH}$ in the low caries risk is all the same at the time interval of the tenth, fifteenth, twentieth, thirtieth and sixtieth. This complies with the study ${ }^{16}$ that showed that there were no differences of saliva $\mathrm{pH}$ change between chewing gum containing sucrose and sorbitol. Significant difference can only happen in patients with low caries risk at the fifth minute, where their saliva $\mathrm{pH}$ decreases lower after consuming snacks containing sucrose compared to maltitol. Saliva $\mathrm{pH}$ increasing at the fifth minute after consuming snacks containing maltitol might be caused by the alkalinity of the milk calcium, sodium bicarbonate, and potassium in snacks. Patients with high caries risk show their saliva $\mathrm{pH}$ decrease significantly lower after consuming snacks containing sucrose compared to snacks containing maltitol at the time interval of tenth, fifteenth, twentieth, thirtieth and sixtieth minute.

This is caused by sucrose being synthesized by Streptococcus mutans forming glucan that has an important role in bacteria metabolization. Furthermore, sucrose can also be fermented homolactically into one glucose molecule and one fructose molecule; later, the glucose is separated into two molecules of lactic acid as the end product. This acid production can reduce the saliva $\mathrm{pH}^{13}$ On the other hand, maltitol cannot be fermented by most organisms inside the mouth; so it could not produce essential acids. ${ }^{12,14}$ There is more acid formation when consuming snacks containing sucrose compared to those containing maltitol. This causes the $\mathrm{pH}$ saliva to decrease even lower.

The insignificant difference at the fifth minute after consuming snacks containing sucrose or maltitol was maybe because of the formation of acid is still at the same level. The significant difference of saliva $\mathrm{pH}$ between the patients having low and high caries risks in the fifth, tenth, fifteenth, twentieth, thirtieth, and sixtieth minutes after consuming snacks containing sucrose shows that the decrease of saliva $\mathrm{pH}$ in patients having high caries risk is more pronounced at the time interval of fifth, tenth, fifteenth, twentieth, thirtieth, and sixtieth minutes from the initial $\mathrm{pH}(0$ minute) compared to the patients having low caries risk. This might be because of those patients with high caries risk have lower initial saliva $\mathrm{pH}$ and also have more amounts of bacteria compared to the patients with low caries risk; so the acid formed increases after consuming snacks containing sucrose.

It was shown that the change in the pattern of saliva $\mathrm{pH}$ in patients having high caries risk would be even lower at the time interval of tenth, fifteenth, twentieth, thirtieth, from the zero minute compared to the patients having low caries risk after consuming snacks containing maltitol. This may happen since patients having high caries risk take a longer time to neutralize acid. Thus, the saliva $\mathrm{pH}$ also took more time to return to the initial $\mathrm{pH}$. The decrease of saliva $\mathrm{pH}$ at the fifth minute in patients with high and low caries risks after consuming snacks containing maltitol are on the same level; this might be due to the same amount of the acid formation initially. The increase of saliva $\mathrm{pH}$ at the sixtieth minute in both high and low caries risks patients close to the initial $\mathrm{pH}$ because maltitol is easily neutralized by the saliva buffer.

\section{CONCLUSION}

The change in the pattern of saliva $\mathrm{pH}$ in patients having high caries risk decreased more compared to patients having low caries risk, both after consuming snacks containing sucrose and maltitol. This study supports the usage of maltitol as sugar replacement since it can reduce the incidence of dental caries, ${ }^{12-14}$ and there were no symptoms seen when using doses of less than $50 \mathrm{~g}$ per day. ${ }^{18}$ Moreover, previous study stated that maltitol was well tolerated in children at $15 \mathrm{~g}$ in one intake. ${ }^{19}$ However, further research must also be undertaken to study regarding the precise safety dose of maltitol in the form of snack and / or chewing gum due to the fact that the saliva $\mathrm{pH}$ will return to normal within one hour and it should include the other group of patients with very low, low, moderately low, high and very high caries risks. Other types of sugar substitutes may also be investigated, for their use as an alternative to sucrose in the food and beverage industries. 


\section{ACKNOWLEDGEMENT}

This study was supported by Endowment Type B (EDW B 10-090-0429) from International Islamic University Malaysia.

\section{REFERENCES}

1. Abelson DC, Mandel ID. The effect of saliva on plaque pH in vivo. J Dent Res 2001; 60: 1634-8.

2. Dodds MWJ, Johnson DA, Yeh CK. Health benefits of saliva: a review. J Dent 2005; 33:223-33.

3. World Health Organization. Research and action for the promotion of oral health within primary health care. Basle, Switzerland: Cibo-Georgy Ltd, 1989:12.

4. Sardana V, Balappanavar AY, Patil GB, et al. Impact of a modified carbonated beverage on human dental plaque and salivary $\mathrm{pH}$ : an in vivo study. J Indian Soc Pedod Prev Dent 2012; 30:7-12.

5. Vehkalahti M, Nikula-Sarakorpi E, Paunio I. Evaluation of saliva tests and dental status in the prediction of caries susceptible increment in caries teenagers. Caries Res 1996; 30:22-8.

6. Shuler CF. Inherited Risks for Susceptibility to Dental Caries [Online]. Available at: http://www.nider.nih.gov/news/consensus.asp. Accessed August 30, 2012

7. Haydersah J, Chevallier I, Rochette I, et al. Fermentation by amylolytic lactic acid bacteria and consequences for starch digestibility of plantain, breadfruit, and sweet potato flours. J Food Sci 2012; 77:M466-M472.

8. Swarn A, Swift EJ Jr. Management of high caries risk patients: part 1- risk assessment. J Esthet Restor Dent 2012; 24:233-5.

9. Bonnie Singleton. Maltitol dangers [online]. availableat:http://www.livestrong.com/article/ 518665-maltitol-dangers/\#ixzz1n4lCPgfl. Accessed August 18, 2011.

10. Thaweboon S, Suddhasthira T, Thaweboon B. Plaque $\mathrm{pH}$ response to snack in children Southeast Asian. J Trop Med Public Health 2007; 38:598-603.

11. Kanchanakamol U, Srisilapanan P, Umpriwan R, Kongmalai A. Dental plaque removal in adults using a newly developed 'Concept 45 degrees toothbrush'. Int Dent J 1993; 43:116-20.

12. Maguirea A, Rugg-Gunna J, Wright G. Adaptation of dental plaque to metabolise maltitol compared with other sweetener. J Dent 2000; 58:51-9.

13. Wolff MS, Larson C. The cariogenic dental biofilm: good, bad or just something to control? Braz Oral Res 2009; 23:31-8.

14. Edwardsson S, Birkhed D, Mejàre B. Acid production from Lycasin, maltitol, sorbitol and xylitol by oral streptococci and lactobacilli. Acta Odontol Scand 1977; 35:257-63.

15. Ismiyatin $\mathrm{K}$, Moetmainah $\mathrm{P}$, Adioro S. Saliva buffer effectivity difference between low caries and high caries patients before and after amalgam restorations. Dental Journal 2003; 36:134-8.

16. Burt BA. The use of Sorbitol-and Xylitolsweetened chewing gum in caries control. J Am Dent Assoc 2006; 137:190-6.

17. Löfgren $C D$, Wickström $C$, Sonesson $M$, Lagunas PT, Christersson C. A systematic review of methods to diagnose oral dryness and salivary gland function. BMC Oral Health 2012; 12:29.

18. Ruskoné-Fourmestraux A, Attar A, Chassard D, Coffin B, Bornet F, Bouhnik Y. A digestive tolerance study of maltitol after occasional and regular consumption in healthy humans. Eur J Clin Nutr 2003; 57:26-30.

19. Thabuis C, Cazaubiel M, Pichelin M, Wils D, Guerin-Deremaux L. Short-term digestive tolerance of chocolate formulated with maltitol in children. Int J Food Sci Nutr 2010; 61:728-3 